\title{
Haji Yusof Rawa dan Penerbitan Majalah al-Islah (1970-1974)
}

\author{
Faisal@Ahmad Faisal Abdul Hamid \\ Universiti Malaya, faisal@um.edu.my \\ Hamidah Jalani \\ Universiti Malaya, hamidahjalani@yahoo.com.my
}

\begin{abstract}
Abstrak
Artikel ini membincangkan penglibatan Haji Yusof Rawa dalam gerakan islah di Tanah Melayu. Perbincangan dalam artikel ini merangkumi biodata ringkas dan keterlibatan beliau dalam usaha-usaha islah melalui penulisan. Setelah itu, sejarah penerbitan Majalah al-Islah juga dibincangkan dalam artikel ini di samping menjelaskan isi kandungan utama majalah yang sarat memuatkan idea-idea islah. Dapatlah disimpulkan bahawa Haji Yusof Rawa banyak menegur dan menyarankan pembaharuan masyarakat Islam di Tanah Melayu melalui penerbitan Majalah al-Islah. Ramai di kalangan membaca dan pendukung islah dalam dekad 70-an merasa gembira dengan kehadiran Majalah al-Islah dan berharap penerbitannya dapat diteruskan namun oleh kerana kekangan dan halangan tertentu Majalah al-Islah terpaksa diberhentikan penerbitannya pada 1974.
\end{abstract}

Kata kunci: Haji Yusof Rawa, Majalah al-Islah, idea-idea islah

Haji Yusof Rawa and the Publication of al-Islah Megazine (1970-1974)

\section{Abstract}

This article discusses the role of Haji Yusof Rawa in the islah movement in Malaya. The discussion in this article encompasses a brief biography of him, and his involvement in islah movement efforts through writing. After that, a brief history of publication of al-Islah Magazine is also discussed in this article besides explaining the main contents of the magazine that are of islah ideas. It can be concluded that Haji Yusof Rawa has advised and reformed the Muslim community in Malaya through the publication of al-Islah Magazine. Many of the readers and supporters in the decade of 70 were delighted with the presence of alIslah Magazine and hoped that their publication would continue but because of the certain limitations and obstacles of al-Islah Magazine had to be repealed in 1974.

Keywords: Haji Yusof Rawa, al-Islah Magazine, ideas of islah 


\section{Pendahuluan}

Kemunculan Majalah al-Islah dalam tahun 1970 merupakan mata rantai dari perkembangan gerakan Islah yang berputik sejak awal abad ke-20 lagi. Perkembangannya terus rancak sejak dari awal abad ke-20 dan terus berkembang hinggalah dalam tahun 70-an penerbitannya mula terbantut. Dengan terbitnya Majalah al-Islah, di mana Haji Yusof bin Haji Abdullah ar-Rawi sebagai penerbit dan pelopor kemunculan majalah tersebut menyambung hayat perjuangan majalah yang berbentuk islah di Malaysia. Islah zaman ini menjadi lebih meluas kerana permasalahan yang menimpa umat Islam begitu ketara dan amat besar. Melalui Majalah alIslah, sasaran yang agak ketara ditonjolkannya ialah menggalakkan orang-orang Melayu mengikuti perkembangan politik, ekonomi, pelajaran dan menggesa mereka agar peka dengan pergolakan yang berlaku di hadapan mata. Matlamat reformasinya juga bukan sahaja untuk mempertahankan kehormatan dan maruah bangsa semata-mata bahkan jauh lebih dari itu cuba mencetuskan rasa kesedaran keagamaan mengenai tanggungjawab yang perlu dimainkan oleh warganegara dalam sesebuah negara. Peristiwa kebangkitan semula Islam yang mula dirasai ketika itu sebelum dimarakkan lagi dengan berlakunya Revolusi Iran pada akhir 70-an banyak memberi pengaruh terhadap perkembangan majalah berorientasikan agama.

Pada masa yang sama, kesedaran di kalangan institusi agama tentang pentingnya bahan bacaan sebagai satu platform menegakkan amar makruf dan nahi mungkar juga turut menyumbang kepada kebangkitan islah ini. Yayasan Dakwah Islamiah Malaysia (Yadim) yang merintis langkah awal ke arah penerbitan majalah agama bergerak secara lebih serius apabila menerbitkan majalah Dakwah (Mac 1977). Langkah kemudiannya diikuti oleh Majlis Agama Islam Sabah dengan menerbitkan alHikmah (Jun 19770) dan Jabatan Agama Islam Perak dengan alRidhwan (September 1978). Sebelum itu, Jabatan Agama Islam Selangor sudah mengeluarkan Hidayah (Mei 1976) dan al-Ehsan (Oktober 1976), sementara Jabatan Agama Islam Terengganu menerbitkan Saujana (Januari 1974).

Kebangkitan semula Islam dan pengaruh Revolusi Iran yang mula berlaku pada akhir dekad 70-an mula menampakkan kesan yang signifikan terhadap dunia permajalahan Melayu. Dua puluh 
tujuh buah majalah agama yang diterbitkan pada dekad ini diterbitkan oleh pertubuhan atau persatuan yang muncul ekoran dua peristiwa penting itu. Pertubuhan yang paling penting ialah alArqam yang ditubuhkan sejak 1968 lagi dan selebar sayap mengembangkan fahaman spiritualnya sehingga cukup kepakaran untuk melibatkan diri di dalam dunia penerbitan majalah dengan menerbitkan Majalah al-Arqam. Kemudian beberapa buah majalah lain turut menyusul seperti al-Munir (Januari 1983), al'Ain (Jun 1984), al-Qalam (Jun 1984), al-Mukminah (Februari 1986), Fardhu 'Ain (April 1987), an-Nasihah (Disember 1987), Imam (Oktober 1988) dan al-Qiadah (Januari 1989). Kesemua majalah al-Arqam ini mengajak kepada audiens supaya menjalani kehidupan seperti yang digariskan oleh Rasulullah SAW.

Buat masa kini punca masalah kemunduran umat Islam telah dikenalpasti oleh tokoh-tokoh pemikir Islam semasa yang pada asasnya berkaitan dengan kritis pemikiran. Mohammad Kamil $\mathrm{Hj}$ Ab. Majid, menyatakan tajdid dan islah malah jihad dan ijtihad pada masa kini seharusnya tertumpu kepada aspek pemikiran dan pemantapan metodologi berfikir. ${ }^{1}$ Di mana pembaharuan tamadun hanya akan tercapai apabila adanya perubahan sikap di kalangan umat terutamanya di kalangan pemimpin politik, intelektual dan ulamanya atas sifat mereka sebagai peneraju umat. Maka di sini para pemikir cuba mencari saluran yang bertepatan untuk dijadikan landasan dalam menyalurkan ideologi bagi mengembangkan proses islah ini.

Oleh itu, penglibatan pemikir-pemikir islah di dalam penerbitan majalah agama sebelum perang amat penting kerana ia mampu menyemai minat terhadap pembacaan di kalangan masyarakat dengan menjadikan satu-satunya media yang membolehkan mereka mengikuti perkembangan semasa di dalam dan luar negara. Di samping itu, aspek keagamaan dan ijtihad dijadikan sebagai nadi pasaran majalah-majalah agama sebagai suatu isu yang hangat diperkatakan pada ketika itu. Disebabkan pasaran majalah yang cukup baik di kalangan masyarakat, tidak hairanlah banyak penerbit menjadikan majalah keluarannya sebagai landasan memberi dan menerima cetusan idea daripada

Mohamad Kamil Hj Ab. Majid, "Gerakan Tajdid: Sejarah dan Perspektif Masa Kini” (Seminar Pengajian Syariah pada 13 - 14 Jun 1995, Fakulti Usuluddin, Akademi Islam, Universiti Malaya), 1. 
para pemikir. Malahan penglibatan pelbagai gerakan islah ini dalam penerbitan majalah juga membuktikan bahawa penerbitan majalah agama mempunyai hubungan yang signifikan dengan kecenderungan semasa, terutama berhubung pembacaan di kalangan masyarakat Melayu.

Ini kerana menurut Sidek Fadzil, sewajarnya gerakan pembaharuan yang meliputi pencerdasan minda perlu diteruskan. Namun, tentunya dengan cara yang sebijaksana mungkin. Pengalaman masa lalu menunjukkan bahawa pembaharuan sering kali berakibat daripada perpecahan sehingga seolah-olah kita berhadapan dengan dilema: bersatu tetapi beku atau berubah tetapi pecah. Jalan keluar dari keserbasalahan ini harus dicari agar matlamat pencerdasan minda dapat dicapai tanpa mengorbankan perpaduan. Gerakan ini harus seiring dengan usaha mendidik dan mendewasakan umat agar bersikap lebih terbuka dalam menghadapi semua perbezaan. ${ }^{2}$

Melalui bahan penerbitan seperti majalah ini, pelbagai isu yang dilontarkan oleh para pengarang yang kebanyakannya berkisar mengenai wanita, agama, ekonomi, politik, sejarah dan sejarawan, sastera serta fenomena kehidupan masyarakat itu sendiri. Banyak majalah yang diterbitkan hasil cetusan idea pemikir bagi menyedar dan mempengaruhi pemikiran masyarakat mengenai ideologi yang dibawa oleh mereka. Contohnya Majalah al-Islah yang akan kita bincangkan secara lanjut, memberi pelbagai segmen dan isu yang menarik antaranya mengenai wanita, pondok, pemikiran, dunia dan sejarah Islam, ketokohan dan sebagainya.

\section{Pengasas dan Penerbit Majalah al-Islah}

Pengasas Majalah al-Islah ialah seorang tokoh reformis yang besar di sebelah utara Malaysia iaitu Haji Yusof bin Haji Abdullah al-Rawi atau lebih dikenali sebagai Haji Yusof Rawa dilahirkan di Lebuh Acheh, Pulau Pinang pada 8 Mei 1922 M bersamaan 10 Ramadan $1340 \mathrm{H}^{3}$ Bapanya, Haji Abdullah bin Haji Noordin al-

2 Sidek Fadzil, "Minda Muslim: Ketegaran dan Keluwesannya" dalam Isu dan Proses Pembukaan Minda Umat Melayu Islam (Dewan Bahasa \& Pustaka, 2002), 53.

3 Bagi pendapat penulis 8 Mei 1922 bersamaan 11 Ramadhan $1340 \mathrm{H}$ pada hari Isnin. Di samping itu juga terdapat pendapat yang menyatakan 6 Mei 1922. 
Rawa adalah seorang peniaga berketurunan Rawa ${ }^{4}$ yang merantau dari Kampung Rawa, Sumatera Barat. Manakala ibunya bernama Hajah Asmah binti Haji Salleh. ${ }^{5}$ Bapanya berdagang kitab suci alQuran, kitab-kitab Arab dan Jawi serta alat-alat kegunaan untuk ibadat seperti tasbih, sejadah dan lain-lain.

Bapanya Haji Abdullah adalah seorang alim dan rajin dalam mengusahakan perniagaan percetakan dan penerbitan yang diberi nama United Press dan Maktabah Haji Abdullah bin Mohd Nordin al-Rawi. Latar belakang Haji Abdullah yang berilmu dan gigih ini banyak mempengaruhi keperibadian Yusof Rawa dalam menuntut ilmu dan maju dalam bidang yang dipilihnya. Maka tidak hairanlah jika Yusof Rawa maju dalam bidang perniagaan sehingga beliau dikaitkan sebagai pengasas kepada Dewan Perniagaan Melayu Pulau Pinang. ${ }^{6}$

4 Istilah "Rawa" pada konteks perbicaraan kita ialah merujuk kepada salah satu etnik suku bangsa Melayu daripada perkataan Rao, satu tempat yang terdapat di Sumatera. Perkataan Rawa hanya popular di Mekah dan Malaysia. Ianya kurang dikenali di Rao sendiri. Hal ini hampir sama dengan suku bangsa Bawean, masyarakat di Malaysia dan Singapura menamakannya Boyan. Sedang istilah Boyan kurang dikenali di Indonesia sendiri. Barangkali penggunaan istilah Rawa di Malaysia bermula daripada Haji Abdullah Noordin al-Rawi yang mengasaskan syarikat percetakan dan penerbit Persama Press pada tahun 1921 di Lebuh Aceh, Pulau Pinang. Pada asalnya disebut "ar-Rawi" mengikut istilah Arab yang bermaksud dibangsakan kepada "Rao" tetapi lama-kelamaan menjadi "ar-Rawa" yang menunjukkan asal seseorang itu, iaitu daripada daerah "Rao", di Sumatera. Tidak terdapat sejarah yang menceritakan orang-orang Rawa yang menuntut atau menetap di lain-lain negeri atau negara menggunakan istilah atau perkataan "Rawi" atau "Rawa" dicantumkan pada bahagian akhir nama mereka. Penggunaannya juga dikatakan digunakan pada sekitar awal abad ke-19 khususnya sewaktu aktiviti pengajian Islam sedang berkembang pesat di Mekah. Lihat lanjut Wan Mohamad Saghir Abdullah, Syeikh Muhammad Murid Rawa dalam Utusan Malaysia bertarikh 19 Mac 2007.

5 Farish A Noor, "Ustaz Haji Yusuf bin Abdullah al-Rawa: Architect of the 'new PAS' of the 1980s". (Farish A Noor adalah salah seorang ahli sains politik dan kemanusiaan. Beliau menjalankan kajian mengenai pembangunan Islam dan menulis sebuah buku bertajuk Pan-Malaysian Islamic Party, PAS. Hajah Asmah meninggal dunia pada tahun 1987 ketika berusia 84 tahun.

6 Badlihisham Mohd Nasir, "Ketokohan dan Pemikiran Dakwah Tuan Haji Yusof Rawa (1922-2000)," (Prosiding Nadwah Ulama Nusantara III Ketokohan dan Pemikiran Ulama Melayu, ed. Farid Mat Zain, Jaffary Awang \& Rabitah Mohd Ghazali, Universiti Kebangsaan Melaysia dan Majlis Agama Islam Negeri Pulau Pinang, 2006), 136-137. 
Beliau mendapat pendidikan awal di Sekolah Rendah Hutan Mayat di Jalan Carnavon sehingga darjah empat. Kemudiannya melanjutkan pelajaran ke Sekolah Charausta ${ }^{7}$ di Transfer Road. Pendidikan menengah bermula di Inggeris Government English School. Ketika di bangku sekolah lagi, Yusof Rawa menunjukkan minat yang cukup tinggi dalam pelajaran dan beliau adalah seorang kanak-kanak yang aktif bersukan khususnya sukan bola sepak yang menjadi kegemarannya. ${ }^{8}$ Kecemerlangannya dalam menguasai bahasa Inggeris menyebabkan beliau ditawarkan untuk melanjutkan pelajaran ke Penang Free School sebuah sekolah elit yang terkenal pada ketika itu. Dan akhirnya berjaya memperolehi Junior Cambridge. Kejayaannya itu menjadi kebanggaan kerana pada ketika itu tidak ramai anak Melayu yang mampu sampai ke tahap itu. Beliau menanamkan cita-cita untuk menjadi peguam dan pegawai tinggi kerajaan seperti yang dilakukan oleh pelajarpelajar terdahulu yang berpendidikan Inggeris. Namun keadaan ini tidak menjadi kebanggaan kepada Haji Abdullah yang lebih kepada pemikiran ortodoks. Beliau bimbang sekiranya Yusof Rawa hanyut apabila terdedah kepada budaya Barat yang diterapkan di sekolah tersebut. Beliau mempunyai agenda tersendiri untuk anak keduanya ini. Bagi beliau, Yusof Rawa mesti menjadi seorang ulama terbilang suatu hari nanti bagi memimpin dan menyambung perjuangan Islam.

Setelah tamat belajar di sekolah Inggeris, bapanya menghantar beliau ke Mekah untuk menyambung pengajian ilmu agama dan bahasa Arab. Di Mekah, beliau menerima pendidikan di Ma'had al-Falah menerusi bidang Usuluddin dan berjaya memperolehi Diploma Takhassus al-Dini dan turut berguru dengan syeikh-syeikh alim dari Nusantara dan tempatan. Pendedahan awal kepada mazhab Syafie dan kemudian mazhab feqah dari aliran Wahabi dan Maliki membuatkan ufuk feqahnya bertambah luas dan dapat mentaufiqkan antara aliran-aliran feqah yang dipelajarinya. ${ }^{9}$ Ini kerana dikatakan pada ketika itu berlakunya ketaasuban yang melampau kepada mazhab feqah

\footnotetext{
7 Shaari Sungib, Biodata Lima Tokoh Perjuangan Pas (Gombak :PAS Gombak \& Penerangan PAS Gombak, t.t.), 20.

8 Mujahid Haji Yusof Rawa, Permata dari Pulau Mutiara (t.tp.: Warathah Haji Yusof Rawa Sdn. Bhd. dan Dewan Muslimat Sdn. Bhd., 2001), 16.

9 Mujahid, Permata dari Pulau Mutiara, 26.
} 
sehingga menyebabkan masyarakat hidup dalam kelompok mazhab yang diikutinya. Sungguhpun begitu, kajian-kajian akidah Ahli Sunnah wal Jamaah yang menjadi teras pengajiannya di Mekah telah membentuk kefahaman akidah beliau kepada permasalahan umat yang pada zamannya melalui zaman kemalapan kerana rata-rata bumi Islam dijajah pada ketika itu. ${ }^{10}$ Di samping itu, beliau turut mengikuti perkembangan pemikiran dunia Islam ketika itu. Pemikiran tokoh-tokoh Islam seperti Jamaluddin al-Afghani, ${ }^{11}$ Muhammad 'Abduh, ${ }^{12}$ Hasan alBanna, ${ }^{13}$ Sayyid Qutb dan lain-lain tokoh Ikhwan diikuti dengan penuh minat. Keadaan ini sedikit sebanyak telah mempengaruhi Yusof Rawa dari segi fikrahnya terhadap Feqah Ibadat dan Feqah Siasah.

Mengikuti perkembangan semasa yang berlaku di dunia Islam telah mengubah perspektif dan banyak mengajarnya erti pemikiran Islam kontemporari. Hasil cetusan hatinya dalam mengenal suasana baru dalam fasa kehidupan menuntut beliau untuk bergerak seiring dengan perubahan semasa. Bermula sebagai seorang mahasiswa, beliau mula melibatkan diri dalam aktiviti pergerakan pelajar. Beliau menganggotai Persatuan Pelajar Melayu Mekah dan pernah menjadi Setiausaha Agung Lembaga Tanah Melayu dalam usaha membantah penubuhan Malayan Union dari luar negara bagi menuntut kemerdekaan negara. Pada tahun 1947, akhirnya Yusof Rawa pulang ke tanah air dengan gabungan ilmu agama dan sekular. Ilmu agama diperolehinya di Mekah sementara ilmu sekular didapatinya ketika berada di alam pendidikan Inggeris dahulu. Adunan dua bidang ilmu inilah yang kemudiannya membentuk personaliti beliau sebagai seorang ulama

${ }^{10}$ Mujahid, Permata dari Pulau Mutiara, 27.

11 Nama sebenar Sayid Jamaluddin al-Afghani ialah Muhammad Jamaluddin alAfghani al-Husaini (1838-1897M) merupakan seorang aktivis politik dan nasionalis Islam di Afghanistan, Iran, Mesir dan Empayar Uthmaniyyah semasa kurun ke-19. Beliau merupakan salah seorang pelopor pemodenan Islam yang berpegang teguh dengan akidah Syiah.

12 Nama sebenar Muhammad Abduh ialah Muhammad bin Abduh bin Hasan Khairullah. Beliau merupakan seorang pakar undang-undang berbangsa Mesir, ilmuan agama, dan reformis pendidikan melalui pengislahan dalam sistem pendidikan.

13 Hassan al-Banna (14 Oktober 1906 - 12 Februari 1949) merupakan seorang reformis sosial dan politik Mesir yang terkenal sebagai pengasas gerakan Jamiat al-Ikhwan al-Muslimun. 
dan juga seorang profesional. Satu personaliti menarik yang amat didambakan oleh pemimpin-pemimpin kita pada hari ini.

\section{Karya Penulisan}

Yusof Rawa banyak menyumbang jasa kepada masyarakat dengan menghasilkan beberapa buah karya yang bermutu. Dengan memiliki syarikat percetakan sendiri beliau tidak mempunyai masalah untuk menerbitkan karyanya sendiri. Syarikat percetakan yang dinamakan Syarikat Percetakan al-Rawa itu dibuka pada tahun 1946 sekembalinya beliau daripada menuntut ilmu di Mekah. Malah sebelum mempunyai syarikat percetakan sendiri, beliau telah pun menulis artikel untuk dihantar ke majalah-majalah di tanah air sedangkan beliau pada ketika itu masih menetap di luar negara. Ini dapat dilihat apabila hasil cetusan ideanya telah tersiar menerusi Warta Jenaka, Warta Malaya ${ }^{14}$ dan Warta Ahad pada tahun 1937.

Di samping itu, beliau turut mengarang buku-buku agama. Selain mengarang, Yusof Rawa juga menerbitkan majalah dwimingguan Majalah al-Islah pada tahun 1970. Al-Islah ini diusahakan bersama sahabatnya seperti Talib Azmi dari Kulim dan Pak Abu dari Kampung Baru, Selangor. Kolum tetap yang dikhaskan untuk tujuan Fikrah Islam yang ketika itu masih baru ialah terjemahan dari buku Ma'àlim fì al-Tarīq dan Fì Zilāl alQur'ān karangan pemikir Islam unggul Sayyid Qutb. ${ }^{15}$ Majalah tersebut telah diedarkan ke seluruh Malaysia, Brunei dan Indonesia. Beliau sendiri menulis di ruangan Tafsir al-Qur'an. ${ }^{16}$

14 Warta Malaya adalah akhbar harian berbahasa Melayu yang dikendalikan oleh Ibrahim Yaakob. Akhbar ini diterbitkan sekitar tahun 1931-1941 iaitu sebelum Perang Dunia II. Ia menjadi media memperjuangkan kemerdekaan Tanah Melayu yang diperjuangkan oleh Kesatuan Melayu Muda. Warta Malaya diterbitkan di Singapura. Editornya ialah Onn Bin Jaafar (1930-1933), Sayyid Alwi bin Sayyid Sheikh al-Hadi (1933-1934), Sayyid Hussein bin Ali Alsagoff (1934-1941) dan Ibrahim Yaakob (1941). Dengan bantuan pihak Jepun, Ibrahim Yaakob telah membeli Warta Malaya ini pada 1941. Ibrahim menjadi agen Jepun pada ketika itu. "Warta Malaya," laman sesawang Wikipedia Ensiklopedia Bebas, dicapai 10 Disember 2009, http://ms.wikipedia.org/wiki/Warta_Malaya.

15 Mujahid, Permata dari Pulau Mutiara, 62.

16 Dalam ruangan tersebut beliau menterjemah Tafsīr fì Zilal al-Qur'ān tulisan Syed Qutub. Bahkan beliau telah menghasilkan sebuah kitab tafsir al-Quran yang diberi nama Tafsir al-Rawi. Tafsir tersebut telah mendapat pengiktirafan 
Selain itu, beliau turut menyebarkan dakwahnya dengan mengarang risalah-risalah perjuangan gerakan Islam seperti Ikhwan al-Muslimun ${ }^{17}$ dan Jama' at Islami ${ }^{18}$ dan diedarkan kepada masyarakat non Muslim di Pulau Pinang. ${ }^{19}$

Manakala buku-buku pelajaran ${ }^{20}$ pula, seperti buku Geografi dalam bahasa Arab, bahasa Melayu, bahasa Inggeris dan Mandarin juga diterbitkan bagi kegunaan sekolah-sekolah agama di Tanah Melayu. Beliau juga tidak ketinggalan menceburi bidang pengajian tafsir dengan menghasilkan sebuah kitab tafsir yang dinamakan Tafsir al-Rawi Juzu' 'Amma. ${ }^{21}$ Selain buku ilmiah yang sarat dengan mutiara ilmu, beliau juga turut menghasilkan sebuah karya yang mempunyai kesusasteraan tinggi antaranya Madah Sukma ${ }^{22}$ yang telah mendapat pujian Pendeta Za'ba. Di samping itu, beliau turut menerbitkan 14 buah buku dan bukunya

daripada Majlis Agama Islam dan Istiadat Melayu Kelantan. la mula dicetak pada tahun 1950 dan telah mendapat sambutan yang menggalakkan daripada orang ramai sehingga diulang cetak beberapa kali.

17 Al-Ikhwan al-Muslimun adalah sebuah gerakan Islam terbesar di zaman moden ini. Seruannya ialah kembali kepada Islam sebagaimana yang termaktub di dalam al-Quran dan al-Sunnah serta mengajak kepada penerapan syariat Islam dalam kehidupan nyata. Dengan tegar gerakan ini telah mampu membendung arus sekularisasi di dunia Arab dan Islam. Gerakan ini dipelopori oleh Hasan al-Banna (1324 - 1368 H/1906 - 1949 M).

18 Jama'at al-Islāmī merupakan satu pergerakan politik Islam yang ditubuhkan oleh Sayyid Abul Ala Maududi pada 24 Ogos 1941 sebagai sebuah parti politik di Pakistan. Tetapi pada hakikatnya ia sebuah jamaah akidah atau harakah Islamiah untuk menegakkan sistem hidup Islam di muka bumi ini. Akidahnya ialah dua kalimah syahadah. Kalimah syahadah ini telah ditafsir dan dihuraikan dengan begitu teliti sehingga ia menjadi teras kepada perjuangan Jama'at al-Islāmī.

19 Mustafa Abdullah, Khazanah Tafsir di Malaysia (Kuala Lumpur: Pro Publishing Services, 2009), 217.

20 Seperti buku Nahu Mandarin, Nahu Bahasa Inggeris, Analisa Tentang Beberapa Masalah Hidup Manusia. Lihat lanjut New Sunday Times, September 19, 1990 "Street of The Malay Traders" .

${ }^{21}$ Karya ini dicetak oleh Maktabah al-Haj Abdullah bin Muhammad Noordin alRawi, 55 Achen Streets, Pulau Pinang. Ia diterbitkan oleh The United Press beralamat di 29 Dato' Keramat Road, Pulau Pinang. Tafsir al-Rawi ini ditulis dengan tulisan Jawi dalam bahasa Melayu. Lihat lanjut analisis yang dijalankan oleh Mustafa, Khazanah Tafsir di Malaysia, 217.

22 Madah Sukma (Impian Nafsu Dan Kesedarannya). Maktabah al-Haj Abdullah bin Mohammad Nur ad-Din ar-Rawi, 55, Acheen Street, Penang. Buku ini mengisahkan mengenai khayalan seorang pemuda terhadap dosa dan neraka ketika berniat untuk pergi bersuka-ria. 
ini telah dipasarkan di Jakarta. Perpustakaan Haji Abdullah bin Muhammad Nordin ar-Rawi salah sebuah penerbit dan toko buku di Pulau Pinang hasil peninggalan ayahnya telah mempamerkan 14 buah buku penerbitannya dan juga hasil-hasil karya penulispenulis Islam yang lain. Pameran buku Melayu itu diadakan dengan anjuran bersama Dewan Bahasa dan Pustaka, penerbitpenerbit Malaysia dan kedutaan besar Malaysia di Republik Indonesia. ${ }^{23}$

\section{Majalah al-Islah}

Majalah ini diberi nama al-Islah bersesuaian dengan namanya yang bertujuan memberikan suatu pembaikan dan pembaharuan ke atas masyarakat Islam di samping "mendukung cita-cita yang cukup besar, membawa tanggungjawab yang cukup berat, ingin berbakti dan berkhidmat kepada ugama, bangsa dan tanah air". ${ }^{24}$ Majalah ini diterbitkan "bertujuan menyeru dan berdakwah selain menyeru umat berbuat baik dan melarang dari melakukan perbuatan-perbuatan mungkar" ${ }^{25}$ dalam cita-cita mengabdikan diri di bidang dakwah Islamiah dalam bentuk tulisan. Ini kerana menurutnya kerana setiap hati manusia itu "selalu melupai tugasnya dan konsep perjuangan hidupnya di muka bumi ini, ialah sebagai hamba Allah yang mesti dihiasi lembaran sejarah hidupnya dengan amal ibadah semata-mata kerana Allah SWT", ${ }^{26}$

${ }^{23}$ Buku-buku yang dipamerkan ialah al-Quran al-Karim dengan tafsiran Jawi bagi bacaan kanak-kanak yang diterjemahkan oleh Abdullah Abbas Nasition, Tafsir ar-Rawi, juzu' 1 \& 2 oleh Ibn Rawi, Sosialisme Islam, oleh Mustafa asSiba'i yang diterjemahkan oleh Hassan Salleh, Simposium Tasawuf dan Tarikat oleh Dr. Burhanuddin Helmi, Ikhtisar Sejarah Perundangan Islam oleh Mohsein bin Haji Mansur, Ringkasan Sejarah Kerajaan Daulah Bani Abbasiyah, Ringkasan Sejarah Kerajaan Daulah Bani Umaiyah, Ringkasan Sejarah Khulafa' ar-Rasyidin, Ringkasan Sejarah Islam di Sepanyol, Ringkasan Nur al-Yaqin yang semuanya disusun oleh Mustafa Abdul Rahman. Dan terdapat dua buah buku baru bertajuk Bagaimana Hendak Mengatasi Dukacita oleh Abu Abdul Latif dan Islam dan Keadilan Sosial oleh Yusuf Ahmad Lubis. Lihat lanjut Majalah al-Islah (Pulau Pinang: Zi United Press, 1970), jil. 1, bil. 10, 19.

24 Yusof Rawa, "Lahir di Tengah Kumandang Suara Suci," Majalah al-Islah, 15 Febuari 1970, 3.

25 Yusof Rawa, "Lahir di Tengah Kumandang Suara Suci," Majalah al-Islah, 3.

26 Yusof Rawa, "Mengucapkan Selamat Tahun Baru Hijriah 1390," Majalah alIslah, 15 Mac 1970, 4. 
Al-Islah ini digambarkan sebagai perjuangannya di tengahtengah dunia persuratkhabaran Islam di tanah air yang bersifat umum dan bebas. Di mana para penulis diberi kebebasan dalam melontarkan idea-idea Islamik sama ada dalam "bentuk rencana, cerpen, sajak, drama dan sandiwara, namun apa yang penting haruslah kita tekankan segala tulisan itu haruslah bercorak keislaman". ${ }^{27}$

Majalah ini diterbitkan ketika di ambang kemasukan tahun baru, tahun 1970. Ini kerana tahun sebelumnya, dianggap sebagai tahun "tunggang balik" atau "kacau bilau."28 Pelbagai peristiwa yang menimpa umat Islam semasa seperti Masjid al-Aqsa dibakar oleh orang-orang Yahudi, ekoran gerakan zionisme, kezaliman oleh Hindu terhadap kaum Muslimin di bandar Ahmad Abad dan sebagainya. Dan apa yang mendukacitakan lagi ialah mengenai peristiwa 13 Mei 1969 yang menimpa masyarakat Tanah Melayu telah mengganggu gugat kehidupan masyarakat Muslim sejagat.

Di samping itu, masalah ummah juga menjadi fokus di dalam penerbitan majalah ini apabila beliau membangkitkan mengenai permasalahan penyakit remaja yang melanda umat Islam pada hari ini. Beliau juga dikatakan sering melontarkan beberapa permasalahan yang patut difahami oleh umat Islam dalam merealisasikan konsep perpaduan ummah. Tulisan beliau seakanakan sebuah tingkap untuk kita menjenguk ke satu daerah yang jarang benar ditinjau, sama ada dari jauh ataupun dekat. Di tambah pula, penerbitan al-Islah juga dilihat sebagai usaha untuk menyebarkan gagasan reformasi dan semangat nasionalisme Melayu Islam yang cuba diterapkan dan mengasak pemikiran masyarakat Melayu ketika itu.

"Oleh kerana itu, kepada seluruh umat negeri ini, baik dari pihak pemerintah dan rakyat jelata, cubalah renungkan sekurang-kurangnya dan cubalah bertindak untuk mengubahkan keadaan yang telah dan sedang dideritai oleh umat negeri ini dengan secepat mungkin, mengikut kemampuan dan kekuasaan yang ada pada kita, sebelum tibanya saat kehancuran..."29

\footnotetext{
27 Yusof, "Lahir di Tengah Kumandang Suara Suci," 3.

28 Yusof Rawa, "Di Ambang Tahun Baru Hijriah 1390," Majalah al-Islah, 1 Mac 1970, 3.

29 Yusof, "Di Ambang Tahun Baru Hijriah 1390," 3.
} 
Al-Islah diterbitkan pada tengah bulanan dengan menggunakan sistem jilid dan bilangan ini sering mengutarakan pelbagai tema Islamik yang mampu menggarap minda pembaca. Dengan menggunakan sistem tulisan Jawi dan purata halaman 16 hingga 32 halaman diterbitkan dengan kekerapan dwi-mingguan bermula dari 15 Febuari 1970 bersamaan 9 Zulhijjah 1389H, 1 Mac 1970, 15 April 1970 dan seterusnya. Majalah ini diterbitkan oleh syarikat percetakan Zi United Press, Pulau Pinang dengan berukuran $7.2 \times 10.1$ inci dengan harga 30 sen senaskhah. Namun mulai jilid keempat sekitar tahun 1973, ukurannya telah ditukar kepada saiz yang lebih kecil iaitu 11 x 7.75 inci dengan harga yang sama.

Penggunaan tulisan Jawi dalam penerbitan al-Islah, menurut Yusof Rawa, tulisan Jawi merupakan asas utama bagi umat Islam yang ingin membaca, memahami dan mempelajari isi-isi kitab suci al-Quran. Beliau berpendapat bahawa adalah menjadi sia-sia diadakan musabaqah al-Quran pada tiap-tiap tahun sekiranya anak-anak yang berada di bangku sekolah tidak tahu membaca tulisan Jawi. Dengan keadaan ini, al-Islah mengambil suatu langkah dalam memartabatkan warisan tulisan Jawi dengan mengaplikasikannya di dalam penerbitan tengah bulanan al-Islah:

"Menurut pendapat kami, kami sebagai penerbit dan pengarang tengah bulanan al-Islah, telah memilih tulisan Jawi sebagai alat untuk menyampaikan dakwah Islamiah di tanah air kita ini..."

Kehangatan al-Islah mula dirasai oleh setiap masyarakat terutamanya generasi berpendidikan Islam. Yusof Rawa sendiri pernah menyatakan bahawa "umat Islam di Malaysia harus menjadikan tahun 1970/1390H sebagai tahun memulakan gerakan dakwah yang lebih cergas, lebih dinamis daripada gerakan di dalam tahun-tahun yang sebelumnya..."31 dan "terbitan ini adalah atas dasar dakwah bukannya atas dasar komersial...",32

Namun kehangatan yang diharap sampai ke petang, tiba-tiba mendung di tengah jalan. Pemikiran yang dibawa Yusof Rawa

30 Yusof, "Mengucapkan Selamat Tahun Baru Hijriah 1390," 20.

31 Yusof Rawa, "Mengharapkan Hijriah 1390 Ini Dijadikan Tahun Berdakwah," Majalah al-Islah, 1 April 1970, 4.

32 Yusof Rawa, "Dari Meja Pengarang," Majalah al-Islah, 15 Febuari/ 1 Mac 1973, 2. 
dalam usaha membangkitkan kesedaran umat Islam Malaysia kepada perlunya kembali kepada Islam dalam penjelasan kontemporari tergendala. Keluarannya telah digantung buat seketika atas dasar kepentingan politik pemerintah. Sebagai seorang pemimpin dalam parti pembangkang, kehadiran al-Islah dikhuatiri menjadi propaganda politik kepada PAS. Sehinggalah sekitar Ogos 1974 majalah ini diberhentikan penerbitan buat selama-lamanya.

\section{Isi Kandungan Majalah al-Islah}

Majalah al-Islah memuatkan pelbagai isu semasa seperti bidang ilmu pengetahuan, kemasyarakatan, politik, ekonomi, pendidikan, tauhid, falsafah dan sebagainya yang bercorak keislaman. Manakala konsep penulisannya pula, penerbit menegaskan bahawa majalah ini mempunyai kebebasan dalam bentuk penyampaiannya. Apa yang penting kebenaran yang hakiki itu perlulah diutamakan dalam setiap aspek.

Sejajar dengan perkembangan Islam di zaman moden ini, islah menjadi sebahagian daripada proses pembudayaan sejarah yang mempunyai kaitan dengan pergerakan reformasi moden golongan Salafiyyah di dunia Arab. Islah dijadikan lambang kepada fenomena evolusi Islam pada akhir abad ke-19. Ia merupakan satu proses yang melahirkan beberapa pergerakan pembaharuan di kalangan tokoh pada waktu itu seperti Jamaluddin al-Afghani, Muhammad 'Abduh ${ }^{33}$ dengan al-Manar, Syeikh alHadi $^{34}$ dalam al-Imam ${ }^{35}$ dan sebagainya.

33 Azman bin Md Zain, Pembinaan Peradaban Ummah Melalui Proses Islah Mengikut Pemikiran Sayyid Jamal al-Din al-Afghani (Disertasi, Universiti Malaya, 2001), 11.

${ }^{34}$ Syed Sheikh bin Ahmad al-Hadi (22 November 1867 - 20 Februari 1934) merupakan pelopor gerakan Kaum Muda di Malaya. Pada tahun 1927, beliau meninggalkan profesion perguruan dan membuka Percetakan Jelutong di Pulau Pinang yang merupakan penerbitan yang bersifat reformasi Islam. Beliau menerbitkan Tafsir Al-Quran oleh Muhammad Abduh dan juga lainlain penerbitan berkaitan artikel dan reformasi. Pada tahun 1926, beliau melancarkan jurnal bulanan, Al-Ikhwan dan pada tahun 1928, beliau menerbitkan akhbar harian, Saudara. Antara penulis untuk akhbar Saudara ialah Abdul Rahim Kajai. Syed Sheikh al-Hadi meninggal dunia pada 20 Februari 1934.

35 Majalah ini merupakan majalah pembaharuan keugamaan yang pertama di Semenanjung Tanah Melayu dan senafas dengan aliran Muhammad Abduh 
Kemudian proses islah ini tidak terhenti di situ sahaja. Keadaan ini diteruskan pula oleh Majalah al-Islah, di mana Tuan Guru Haji Yusof bin Haji Abdullah al-Rawa (8 Mei 1922 - 28 April 2000) sebagai penerbit dan pelopor kemunculan majalah tersebut. Islah zaman ini menjadi lebih meluas kerana permasalahan yang menimpa umat Islam begitu ketara dan amat besar. Melalui Majalah al-Islah ini, matlamat reformasinya bukan sahaja untuk mempertahankan kehormatan dan maruah bangsa bahkan mencetuskan rasa kesedaran keagamaan mengenai tanggungjawab yang perlu dimainkan oleh warganegara dalam sesebuah negara.

"Sungguh serasakan kita ini sedang melintas, melintasi satu segenting waktu, waktu peralihan, peralihan dari kala (period) kehilangan punca kepada kala kecemerlangan suasana, di mana dan bila mana syariat Allah kembali diterima dan undang-undang Allah kembali bergema dalam segenap percaturan hidup kita." 36

Di masa kini, punca masalah kemunduran umat Islam telah dikenal pasti oleh tokoh-tokoh pemikir Islam semasa pada asasnya ialah kritis pemikiran. Justeru itu, tajdid dan islah malah jihad dan ijtihad pada masa kini seharusnya menumpukan kepada aspek pemikiran dan memantapkan metodologi berfikir. Ertinya, pembaharuan tamadun hanya akan tercapai apabila adanya perubahan sikap di kalangan umat terutamanya pada kalangan pemimpin politik, intelektual dan ulamanya atas sifat mereka sebagai peneraju umat. Maka di sini para pemikir cuba mencari saluran yang bertepatan untuk dijadikan landasan dalam menyalurkan ideologi bagi mengembangkan proses islah ini.

Oleh itu penglibatan pemikir-pemikir islah di dalam penerbitan majalah agama sebelum perang amat penting kerana ia

dan majalah al-Manar di Cairo. Diterbitkan di Singapura pada 22 Julai 1906. Antara pengarangnya ialah Syeikh Mohd Tahir Jalaluddin al-Azahari, Syed Syeikh bin Ahmad al-Hadi dan Haji Abbas bin Mohd Toha. Ditulis dengan huruf Jawi. Dicetak mula-mula oleh Matbaah Melayu Tanjung Pagar kemudian diambil alih oleh al-Imam Printing Company Ltd. Berukuran lebar 6.3 inci, panjang 8.6 inci. Mengandungi 32 halaman dan dikategorikan sebagai majalah bulanan. Penerbitannya diberhentikan pada 25 Dis 1908 iaitu selepas dua tahun beroperasi. Naskhah tersimpan di Dewan Bahasa dan Pustaka.

36 Yusof Rawa, "Sepanjang Manakah Lagi...Kiranya?," Majalah al-Islah, 15 Jun/1 Julai 1972, 14. 
mampu menyemai minat di kalangan pembaca dengan menjadikan satu-satunya media yang membolehkan mereka mengikuti perkembangan semasa di dalam dan luar negara. Di samping itu, aspek keagamaan dan ijtihad dijadikan sebagai nadi pasaran majalah-majalah agama menjadi sebagai suatu isu yang hangat diperkatakan pada ketika itu. Disebabkan pasaran majalah yang cukup baik di kalangan masyarakat, tidak hairanlah banyak penerbit menjadikan majalah keluarannya sebagai landasan memberi dan menerima cetusan idea daripada para pemikir. Malahan penglibatan pelbagai gerakan islah ini dalam penerbitan majalah juga membuktikan bahawa penerbitan majalah agama mempunyai hubungan yang signifikan dengan kecenderungan semasa, terutama berhubung pembacaan di kalangan masyarakat Melayu.

Melalui bahan penerbitan seperti majalah ini, pelbagai isu yang dilontarkan oleh para pengarang yang kebanyakannya berkisar mengenai wanita, agama, ekonomi, politik, sejarah dan sejarawan, sastera serta fenomena kehidupan masyarakat itu sendiri. Banyak majalah-majalah yang diterbitkan hasil cetusan idea pemikir bagi menyedar dan mempengaruhi pemikiran masyarakat mengenai ideologi yang dibawa oleh mereka. Contohnya Majalah al-Islah yang akan kita bincangkan nanti, memberi pelbagai segmen dan isu-isu yang menarik.

\section{Harapan dan Sokongan Kepada Majalah al-Islah}

Tokoh-tokoh politik, ahli perniagaan dan para sasterawan tanah air telah mengalu-alukan kelahiran al-Islah. Antara tokoh-tokoh politik yang telah memberikan ucapan tahniah dan kata-kata aluan ialah seperti:

"Saya mengharapkan al-Islah dapat memainkan peranannya sesuai dengan namanya al-Islah yang membawa erti perdamaian. Di samping itu, diharap al-Islah juga dapat mempertahankan perasaan muhibah yang telah sedia ada di kalangan rakyat negeri ini. Selain daripada itu, al-Islah juga diharap dapat mempertahankan dasar bebas yang menjadi haluan cita-citanya diterbitkan". ${ }^{37}$

(Syed Ahmad Syihabuddin, Menteri Besar Kedah)

37 Ibrahim Bitu, "Kelahiran Tengahbulanan al-Islah Dialu-alukan: Semoga alIslah Menjadi Pendamai Yang Adil”, Majalah al-Islah, 1 Mac 1970, 13. 
Menteri Besar Perlis, Syeikh Ahmad bin Muhammad Hashim, dalam kata-kata aluannya juga berharap agar al-Islah dapat memainkan peranan pentingnya yang ikhlas untuk menerangkan kebaikan dan ketinggian ugama yang maha suci. "Saya berharap al-Islah tidak akan berat sebelah ke mana-mana pihak". 38

Encik Husin Abdul Rahman, salah seorang anggota dalam Dewan Undangan Negeri Perlis turut memberi harapan kepada "al-Islah agar menjadi tengah bulanan yang bebas, menerima dan menyuarakan fikiran-fikiran yang bebas, tidak diganggu oleh sesiapa pun."39

Begitu juga Usman Abdullah Perlis, anggota Dewan Rakyat Perikatan kawasan Perlis Utara turut menyuarakan hasratnya terhadap al-Islam:

“...berharap al-Islah akan menjadi bacaan umum sesuai dengan kehendak zaman yang memerlukan lebih pesat, perpaduan yang lebih kukuh dan kesedaran yang lebih mendalam terhadap keselamatan negara." 40

Mustafa Ismail, Setiausaha Dewan Perniagaan Melayu Kedah pun turut mengalu-alukan kelahiran al-Islah ini. Beliau menyatakan rasa "gembira kerana tengah bulanan ini diusahakan oleh orang Melayu." ${ }^{41}$ Ini kerana menurut beliau, Dewan Perniagaan Melayu sentiasa akan memberi dorongan dan galakkan apa sahaja jenis perniagaan yang diusahakan oleh kaum Melayu. Di samping itu beliau juga mengharapkan "al-Islah ini akan menjadi tengah bulanan yang adil dan saksama."

Selain itu, terdapat juga respons positif daripada para pembaca. Antaranya dari Sadik bin Abdullah dari Sekolah Menengah Rendah, Kuala Krai, Kelantan memberikan pendapat bahawa "kehadiran al-Islah ini benar-benar bersifat islah, padat, bernas dan amat menarik minat saya". ${ }^{43}$ Ismail Abdullah dari Manabil Ulum, Penanti turut menyatakan bahawa "semoga dengan kehadiran al-Islah dapat meniupkan roh Islam yang sebenarnya ke

38 Ibrahim, "Kelahiran Tengahbulanan al-Islah Dialu-alukan," 13.

39 Ibrahim, "Kelahiran Tengahbulanan al-Islah Dialu-alukan," 13.

40 Ibrahim, "Kelahiran Tengahbulanan al-Islah Dialu-alukan," 13.

41 Ibrahim, "Kelahiran Tengahbulanan al-Islah Dialu-alukan," 13.

42 Ibrahim, "Kelahiran Tengahbulanan al-Islah Dialu-alukan," 13.

43 Yusof Rawa, “Anda dan al-Islah”, Majalah al-Islah, 1 Jun 1970, 19. 
dalam jiwa masyarakat Islam yang lebih dinamis dan progresif di dalam segenap bidang". ${ }^{4}$

Seorang dari pembaca, Muhammad Nur Haji Salleh dari Jalan Muhammad Amin, Johor Bahru dengan penuh yakin menyatakan bahawa "tengah bulanan al-Islah akan berguna kepada muda mudi dalam usaha membentuk keperibadian bangsa dan agama berasaskan ilmu pengetahuan moden." 45 Beliau turut mengharapkan "agar orang Melayu umumnya dapat membuang fikiran-fikiran lama yang menghalangi pembangunan dan kemajuan masyarakat."

Imam Masjid Negara Kuala Lumpur, Tuan Guru Haji Fathullah Harun telah memberikan komentarnya mengenai kehadiran al-Islah ini. Menurutnya mudah-mudahan al-Islah akan membawa islah dalam erti kata yang sepenuhnya kepada masyarakat Islam di negara kita sekarang ini. Ini kerana menurutnya "masyarakat Islam negara kita, pada umumnya sedang tenggelam dalam lautan (fasad) yang melakukan kerja-kerja di bawah bimbingan syaitan, sehingga terkeluar dari batas-batas syariat Islamiah." ${ }^{\prime 4}$

Seorang lagi pembaca, iaitu Ahmad Maliki, Yang Dipertua Jabatan Hal Ehwal Agama, Pulau Pinang dan Seberang Prai di dalam suratnya telah mendoakan "agar al-Islah bertambah maju dan dapat berdiri di tengah-tengah masyarakat sebagai satu penyuluh umat ke arah al-Islah pada serba-serbinya." ${ }^{\text {48 }}$ Begitu juga Usman Awang dari Pengasuh menyatakan kepada al-Islah rasa kegembiraannya dengan kemunculan majalah ini dapat membendung krisis moral dan fikiran manusia.

"Dalam zaman yang penuh dengan krisis moral dan fikiran manusia begitu jelas melihat sains dan kemajuan-kemajuan teknologi, di samping membuat bermacam-macam hingga melupai soal-soal moral dan akhlak, maka lahirnya al-Islah untuk mengislahkan masyarakat sekarang yang bagi setengah orang mengatakan sangat buruk." 49

\footnotetext{
${ }^{44}$ Yusof, “Anda dan al-Islah", 19.

45 Yusof, "Anda dan al-Islah", 19.

46 Yusof, "Anda dan al-Islah", 19.

47 Pengarang al-Islah, “Anda dan al-Islah”, Majalah al-Islah, 15 Mac 1970, 17.

48 Pengarang, "Anda dan al-Islah", 17.

49 Pengarang, “Anda dan al-Islah”, 18.
} 
Tahun dari tahun al-Islah tidak sunyi dari surat-surat peminat yang menyokong penuh kelahiran tengah bulanan al-Islah ini. Muhammad Nur Haji Saleh berasal dari Johor Bahru, menyatakan rasa gembira dengan kehadiran al-Islah.

"Begitu yakin bahawa tengah bulanan al-Islah akan berguna kepada muda mudi dalam usaha membentuk keperibadian bangsa dan agama berasaskan ilmu pengetahuan moden... orang Melayu juga diharapkan dapat membuang fikiranfikiran lama yang menghalangi pembangunan dan kemajuan masyarakat." 50

Dan apa yang menjadi keistimewaan kepada Majalah al-Islah ini berbeza dengan makalah yang lain adalah kerana setiap artikel yang tersiar di dalam majalah ini tidak menerima sebarang bayaran. Ini kerana penerbit majalah ini berpegang kepada prinsip "setiap ibadah yang kita lakukan, setiap derma bakti yang kita curahkan, bukanlah untuk mencari nama, mencari pangkat, mencari bintang di sisi makhluk manusia, tetapi ialah kerana Allah dan untuk Allah semata-mata". ${ }^{51}$ Keadaan ini sendiri diakui sendiri oleh anak bongsu beliau, Dr. Mujahid Yusof Rawa di dalam bukunya, Permata Dari Pulau Mutiara.

\section{Penutup}

Pada pendapat penulis, Yusof Rawa adalah salah seorang tokoh islah yang mempunyai jati diri yang gigih dalam menyemaikan semangat Islam di dalam diri setiap individu Muslim. Walaupun beliau lebih dikenali sebagai seorang ahli politik Islam, namun sejarah pemikiran yang dibawanya melangkaui bidang yang diceburinya. Ini kerana asas pemerintahan dijadikan sebagai saluran dalam menyuarakan ideologi dalam membangunkan masyarakat Islam.

Justeru itu, untuk mencapai hasrat dan tanggungjawab dalam memperjuangkan menegakkan daulah Islamiah dengan penuh kesedaran bukanlah suatu perkara yang mudah. Pelbagai rintangan terpaksa dihadapi dan memerlukan kepada persiapan-persiapan yang menyeluruh. Persiapan dalam pembangunan fizikal dan organisasi, persiapan kesedaran, pemikiran, keilmuan serta

50 Pengarang, “Anda dan al-Islah", 19.

51 Yusof Rawa, "Mengucapkan Selamat Tahun Baru Hijriah 1390!," Majalah alIslah, 15 Mac 1970, 4. 
kesediaan rohaniah yang tinggi dan kesetiaan kepada perjuangan berlandaskan syariat menjadi peneraju utama sesuatu kejayaan yang hakiki.

Di samping itu juga, ulama dan intelektual Islam hendaklah menjadi gabungan tenaga yang penting dalam usaha memupuk dan meningkatkan kesedaran Islam di kalangan ummah. Bagi Yusof Rawa tidak kira di aliran mana sekalipun kita berada apa yang penting ialah menghormati dan "menilai kata-kata orang tua, gunakanlah pertimbangan dua daun dacing, jasmaniah dan rohaniah,"52 dalam mencari kebenaran kerana mereka lebih berpengalaman dan terlebih dahulu makan garam.

Justeru itu, seluruh tenaga mestilah turut serta secara proaktif dalam membantu para ulama dan intelektual Islam melaksanakan tanggungjawab yang diamanahkan kepada mereka. Bak kata tokoh penerbit ini lagi "ajarkanlah yang tidak tahu, peringatkanlah yang kita lupa dan tunjukkanlah yang benar itu benar supaya kita ikut dan yang salah itu salah, supaya kita jauhinya dan begitulah selanjutnya." 53

\section{Rujukan}

Azman bin Md Zain, "Pembinaan Peradaban Ummah Melalui Proses Islah Mengikut Pemikiran Sayyid Jamal al-Din alAfghani" (Disertasi, Universiti Malaya, 2001).

Badlihisham Mohd Nasir, "Ketokohan dan Pemikiran Dakwah Tuan Haji Yusof Rawa (1922-2000)," (Prosiding Nadwah Ulama Nusantara III Ketokohan dan Pemikiran Ulama Melayu, ed. Farid Mat Zain, Jaffary Awang \& Rabitah Mohd Ghazali, Universiti Kebangsaan Melaysia dan Majlis Agama Islam Negeri Pulau Pinang, 2006), 136-137.

Farish A Noor, "Ustaz Haji Yusuf bin Abdullah al-Rawa: Architect of the 'new PAS' of the 1980s".

Ibrahim Bitu, "Kelahiran Tengahbulanan al-Islah Dialu-alukan: Semoga al-Islah Menjadi Pendamai Yang Adil," Majalah alIslah, 1 Mac 1970, 1.

Majalah al-Islah (Pulau Pinang: Zi United Press, 1970), jil. 1, bil. $10,19$.

\footnotetext{
52 Yusof Rawa, "Secupak Tidak Jadi Segantang," Majalah al-Islah, 1 Jun 1973, 5.

53 Yusof, "Mengucapkan Selamat Tahun Baru Hijriah 1390!," 4.
} 
Mohamad Kamil Haji Ab. Majid, "Gerakan Tajdid: Sejarah dan Perspektif Masa Kini”" (Seminar Pengajian Syariah pada 13 - 14 Jun 1995, Fakulti Usuluddin, Akademi Islam, Universiti Malaya.

Mujahid Haji Yusof Rawa, Permata dari Pulau Mutiara (t.tp.: Warathah Haji Yusof Rawa Sdn. Bhd. dan Dewan Muslimat Sdn. Bhd., 2001).

Mustafa Abdullah, Khazanah Tafsir di Malaysia (Kuala Lumpur: Pro Publishing Services, 2009).

New Sunday Times, September 19, 1990 "Street of The Malay Traders."

Shaari Sungib, Biodata Lima Tokoh Perjuangan Pas (Gombak :PAS Gombak \& Penerangan PAS Gombak, t.t.).

Sidek Fadzil, "Minda Muslim: Ketegaran dan Keluwesannya" dalam Isu dan Proses Pembukaan Minda Umat Melayu Islam (Dewan Bahasa \& Pustaka, 2002).

Yusof Rawa, "Dari Meja Pengarang," Majalah al-Islah, 15 Febuari/ 1 Mac 1973.

Yusof Rawa, "Di Ambang Tahun Baru Hijriah 1390," Majalah alIslah, 1 Mac 1970.

Yusof Rawa, "Lahir di Tengah Kumandang Suara Suci," Majalah al-Islah, 15 Febuari 1970.

Yusof Rawa, "Mengharapkan Hijriah 1390 Ini Dijadikan Tahun Berdakwah," Majalah al-Islah, 1 April 1970.

Yusof Rawa, "Mengucapkan Selamat Tahun Baru Hijriah 1390!," Majalah al-Islah, 15 Mac 1970.

Yusof Rawa, "Mengucapkan Selamat Tahun Baru Hijriah 1390," Majalah al-Islah, 15 Mac 1970.

Yusof Rawa, "Mengucapkan Selamat Tahun Baru Hijriah 1390", Majalah al-Islah, 15 Mac 1970.

Yusof Rawa, "Secupak Tidak Jadi Segantang," Majalah al-Islah, 1 Jun 1973.

Yusof Rawa, "Sepanjang Manakah Lagi...Kiranya?," Majalah alIslah, 15 Jun/1 Julai 1972. 